\title{
PENILAIAN PERILAKU CUCI TANGAN, PENYIMPANGAN PERKEMBANGAN DAN DETEKSI STUNTING MENGGUNAKAN KARTU MENUJU SEHAT
}

\author{
Antarini' ${ }^{1}$ Eka Safitri Yanti ${ }^{\star *}$ \\ 1,2Jurusan Kebidanan, Poltekkes Kemenkes Pangkalpinang, Indonesia \\ *Korespondensi email ekasafitriyanti89@gmail.com
}

\section{ABSTRACT HANDWASHING BEHAVIOR ASSESSMENT, DEVELOPMENTAL DEVIATION AND STUNTING DETECTION USING CARD TOWARDS HEALTHY}

Background: School-age children are a critical age group because at that age they are prone to health problems related to personal hygiene such as diarrhea, toothache, skin diseases and so on. Apart from personal hygiene issues, one of the risks of health problems that can cause growth and development problems for Kindergarten-aged children is nutrition. It is important for child development deviations to be detected early so that it can be quickly corrected for subsequent age development. Anthropometrically, assessing the nutritional status of school-age children can use the weight and height. A tool for monitoring the development of nutritional status of kindergarten children is Kartu Menuju Sehat (KMS). Every child who is measured for height can immediately know their nutritional status. This study looked at a description of hand washing behavior, developmental deviations and stunting detection in kindergarten children.

Purpose To assess hand washing behavior, developmental deviation and stunting detection in kindergarten children through KMS monitoring.

Methods: The type of research used in this research was descriptive research. The research method used was a survey with a cross sectional approach. A total of 29 kindergarten children were assessed for hand washing behavior using WHO guidelines and assessed for stunting status using KMS Dinding.

Results: The results of the study were mostly boys (51.7\%) with ages 2 - 4 years, which is $62.1 \%$. The results of the practice of washing children's hands using hand washing guidelines from the WHO obtained data as much as 21 children (75\%) had been implemented well ( 6 - 7 steps) and less well by $7.1 \%$. Early detection of child deviations using the Developmental Pre-Screening Questionnaire was 16 children (55.2\%) according to development, but there were 9 children (31\%) doubting results and 4 children (13.8\%) likely to experience deviations. The results of measurements using KMS Dinding in kindergarten showed that there were $6.9 \%$ of children's measurement results in yellow, light green $86.2 \%$ and dark green of $6.9 \%$.

Conclusion: KMS Dinding can detect stunting in kindergarten children, there are children who may experience deviations and most children have washed their hands properly according to WHO guidelines

Suggestion provide motivation for students to get used to washing hands using soap in the school and home environment, in order to prevent diseases caused by dirty hands. The school is expected to continue to carry out early detection of children's growth and development so that improvements can be made immediately if a deviation is found in the child's growth and development

Keywords: Hand Washing, Developmental Deviation, Nutritional Status

\section{ABSTRAK}

Latar Belakang: Anak usia sekolah merupakan kelompok usia yang kritis karena pada usia tersebut rentan terkena masalah kesehatan terkait personal hygiene misalnya diare, sakit gigi, penyakit kulit dan sebagainya. Selain masalah personal hygiene, salah satu risiko masalah kesehatan yang dapat menyebabkan gangguan pertumbuhan dan perkembangan anak usia Taman Kanak-Kanak (TK) adalah masalah gizi. Penyimpangan perkembangan anak penting untuk dideteksi secara dini agar dapat dengan cepat dilakukan koreksi terhadap perkembangan usia selanjutnya . Secara antropometri penilaian status gizi anak usia sekolah dapat menggunakan indeks Berat Badan (BB) dan Tinggi Badan (TB). Alat untuk memantau perkembangan status gizi anak TK adalah Kartu Menuju Sehat (KMS). Setiap anak yang diukur TB dapat segera diketahui status gizinya. Penelitian ini melihat gambaran perilaku cuci tangan, penyimpangan perkembangan dan deteksi stunting pada anak taman kanak-kanak. 


\section{JKM (Jurnal Kebidanan Malahayati),Vol 7,No.2.April 2021, ISSN (Print) 2476-8944 ISSN (Online) 2579-762X, Hal 310-318}

Tujuan: Menilai perilaku cuci tangan, peyimpangan perkembangan dan deteksi stunting pada anak taman kanak-kanak melalui pemantauan KMS.

Metode: Jenis penelitian yang digunakan dalam penelitian ini adalah jenis penelitian deskriptif. Metode penelitian yang yang digunakan adalah survey dengan pendekatan cross sectional. Sebanyak 29 anak TK dinilai perilaku cuci tangan menggunakan pedoman WHO dan dinilai status stunting menggunakan KMS Dinding.

Hasil: Hasil penelitian sebagian besar yaitu anak berjenis kelamin laki-laki $(51,7 \%)$ dengan usianya adalah usia 2 - 4 tahun yaitu sebesar $62,1 \%$. Hasil praktik mencuci tangan anak dengan menggunakan pedoman cuci tangan dari WHO diperoleh data sebanyak 21 anak (75\%) telah melaksanakan dengan baik (6 - 7 langkah) dan kurang baik sebesar 7,1\%. Deteksi dini penyimpangan anak dengan menggunakan Kuesioner Pra Skrining Perkembangan (KPSP) sebanyak 16 anak $(55,2 \%)$ sesuai dengan perkembangan, namun terdapat 9 anak $(31 \%)$ meragukan dan 4 anak $(13,8 \%)$ kemungkinan mengalami penyimpangan. Hasil pengukuran menggunakan KMS dinding pada sekolah TK menunjukkan bahwa terdapat sebesar 6,9\% hasil pengukuran anak berada pada warna kuning, hijau muda $86,2 \%$ dan hijau tua sebesar 6,9\%.

Kesimpulan: KMS Dinding dapat mendeteksi terjadinya stunting pada anak TK, terdapat anak yang kemungkinan mengalami penyimpangan dan sebagian besar anak telah mencuci tangan dengan baik sesuai dengan pedoman $\mathrm{WHO}$

Saran memberikan motivasi pada siswa untuk membiasakan diri cuci tangan menggunakan sabun di lingkungan sekolah dan rumah, guna mencegah timbulnya penyakit yang disebabkan oleh tangan yang kotor. Pihak sekolah diharapkan terus dapat melakukan deteksi dini tumbuh kembang anak agar dapat segera dilakukan upaya perbaikan jika ditemukan kondisi penyimpangan pada tumbuh kembang anak

Keywords: Cuci Tangan, Penyimpangan Perkembangan, Status Gizi

\section{PENDAHULUAN}

Anak usia sekolah merupakan kelompok usia yang kritis karena pada usia tersebut rentan terkena masalah kesehatan misalnya diare, sakit gigi, penyakit kulit dan sebagainya (Ardhiyarini, 2008). Anak usia sekolah dikatakan kelompok berisiko (at risk) ketika anak memiliki kondisi biologis, psikologis atau sanitasi lingkungan yang buruk sehingga anak berisiko untuk mengalami gangguan fisik, kognitif, atau perkembangan psikososial. Masalah kesehatan fisik tersebut pada umumnya dikarenakan karena kurangnya pengetahuan dan kurang pedulinya anak usia taman kanak-kanak (TK) akan kebersihan diri (personal hygiene) (Maurer \& Smith, 2013)

Masalah kesehatan yang dapat ditimbulkan dari anak yang kurang memperhatikan personal hygiene yaitu masalah fisik seperti misalnya kurangnya kesehatan gigi dan mulut, penyakit kulit, infeksi pada mata dan telinga, dan gangguan fisik pada kuku.(Satria,2017). Salah satu pengendalian dan pencegahan infeksi yang paling efektif dilakukan adalah dengan menjaga kebersihan tangan. Salah satu cara pengaplikasian kebersihan tangan adalah dengan cuci tangan. Cuci tangan adalah menggosok seluruh permukaan tangan dengan kuat, diikuti dengan membasuh tangan di bawah air mengalir selama 15 detik. Prinsip fundamental dengan mencuci tangan adalah menghilangkan mikroorganisme dari tangan dengan mmembasuhnya di bawah air mengalir walaupun hal ini tidak membunuh mikroorganisme. (Novieastari, Ibrahim, Deswani, \& Ramdaniati, 2020). Oleh sebab itu, permasalahan tersebut dapat diupayakan penanggulangan agar kesadaran akan personal hygiene dengan mencuci tangan dapat meningkat dan kesehatan juga akan meningkat.

Selain masalah personal hygiene, salah satu risiko masalah kesehatan yang dapat menyebabkan gangguan pertumbuhan dan perkembangan anak usia taman kanak-kanak (TK) adalah masalah gizi. Allender, Rector, \& Warner (2010) menjelaskan bahwa masalah gizi merupakan salah satu masalah kesehatan pada anak usia anak TK. Pertumbuhan dan perkembangan anak dipengaruhi oleh beberapa faktor, salah satunya adalah faktor gizi. (Edelman \& Mandle, 2010).

Pemantauan perkembangan usia anak prasekolah merupakan tahap yang penting karena dapat menentukan kualitas Kesehatan, kesejahteraan, pembelajaran dan perilaku di masa mendatang. Dengan ditemukan secara dini penyimpangan perkembangan maka akan dapat lebih cepat ditangani dan segera dikoreksi sehingga anak diharapkan dapat segera menyusul perkembangan anak seusianya (Ulfa, 2018).

Anak usia anak TK yang mengalami masalah gizi rentan terhadap suatu penyakit. Grodner \& Walkingshaw, (2007) menyatakan masalah gizi (malnutrition) dikelompokkan menjadi 
gizi lebih (overnutrition) dan gizi kurang (undernutrition). Berat badan lebih (overweight) dan obesitas merupakan masalah gizi yang utama pada anak - anak dan dewasa di Amerika Serikat (Edelman \& Mandle, 2010).

Berdasarkan data Riskesdas tahun 2018, prevalensi balita stunting di Indonesia menunjukkan 30,8\% atau sekitar 7 juta balita menderita stunting. Keadaan ini lebih lebih besar dari batas maksimal prevalensi stunting yang telah ditetapkan oleh WHO yaitu 20\%. Prevalensi balita stunting di Provinsi Kepulauan Bangka Belitung sebesar 23,37\%, dan ini menurun dibandingkan dengan hasil Riskesdas tahun 2013, yaitu $28,66 \%$. Sedangkan untuk balita wasting (kurus) berdasarkan hasil Riskesdas 2013, Provinsi Kepulauan Bangka Belitung masuk kategori serius, yaitu $10-14 \%$ berdasarkan WHO, 2010. Namun, berdasarkan Riskesdas 2018, prevalensinya menurun menjadi $9,87 \%$.

Stunting adalah kondisi gagal tumbuh pada anak balita akibat dari kekurangan gizi kronis sehingga anak terlalu pendek usianya. Kekurangan gizi terjadi sejak bayi dalam kandungan dan pada awal bayi baru lahir. Kondisi Stunting baru akan tampak setelah bayi berusia 2 tahun. Stunting adalah balita dengan panjang badan ( $\mathrm{PB} / \mathrm{U})$ atau tinggi badan (TB/U) menurut umurnya dibandingkan dengan standard baku WHOMGRS (Multicentre Growth Reference Study) (Wright, et al., 2018).

Status gizi dapat dipengaruhi oleh beberapa faktor diantaranya ekonomi keluarga (pekerjaan dari orang tua, produksi pangan, kondisi perumahan (sanitasi perumahan), pendidikan orang tua, ketersediaan pangan, sumber daya alam, fisik dan manusia (Supariasa, Bakri, \& Fajar, 2010). Masalah gizi dipengaruhi langsung oleh faktor konsumsi makanan dan penyakit infeksi. Secara tidak langsung dipengaruhi oleh pola asuh, ketersediaan dan konsumsi pangan beragam, faktor sosial-ekonomi, budaya dan politik (Harjatmo, Par'i, \& Wiyono, 2017).

Pemantauan pertumbuhan anak dilakukan posyandu secara rutin. Namun anak usia 3-5 tahun sudah memasuki usia taman kanak-kanak (TK) jarang dibawa ke posyandu sehingga pertumbuhannya tidak terpantau. Anak usia 3-5 tahun yang sudah memasuki usia TK mengalami pertumbuhan yang stagnan, perubahan pola makan karena sudah mengenal makanan jajanan namun aktifitasnya tinggi sehingga rawan mengalami gangguan gizi. Padahal mereka tergolong kelompok rawan gizi khususnya dalam hal pertumbuhan (AL-Rahmad, Miko, \& Hadi, 2013)
Perilaku gizi pada anak usia sekolah dapat di perbaiki atau ditingkatkan dengan promosi kesehatan tentang gizi. Promosi kesehatan diartikan sebagai suatu usaha memperbaiki, memfasilitasi individu atau masyarakat dalam mengubah perilaku sehingga memungkinkan tercapainya tujuan yang diinginkan, serta meningkatkan kesejahteraan dan menurunkan biaya perawatan (Pender, Murdaugh, \& Parsons, 2011; Edelman dan Mandle, 2010)

Bentuk promosi kesehatan di sekolah Indonesia adalah Usaha Kesehatan Sekolah (Notoatmodjo, 2010). Kegiatan UKS meliputi pendidikan kesehatan, pelayanan kesehatan dan pembinaan lingkungan sekolah sehat. Ruang Lingkup kegiatan UKS dikenal dengan TRIAS UKS. Pelayanan kesehatan dilaksanakan secara menyeluruh dengan mengutamakan kegiatan promotif dan preventif serta didukung kegiatan kuratif dan rehabilitatif. Pembinaan lingkungan kehidupan sekolah sehat meliputi meningkatkan faktor pelindung (gedung, halaman, warung sekolah, keteladanan guru, menciptakan suasana dan hubungan yang akrab dan erat antara sesama warga sekolah dan masyarakat) dan memperkecil faktor risiko meliputi pagar pengaman, bangunan sekolah yang aman, kawasan bebas rokok, bebas pornografi, pengadaan kantin sekolah (Departemen Kesehatan RI, 2007).

Salah satu program UKS adalah pemantauan personal hygiene dengan praktik cuci tangan dan status gizi siswa. Status gizi seorang anak dapat dilihat dari beberapa segi. Secara antropometri penilaian status gizi anak usia sekolah dapat menggunakan indeks BB dan TB. Alat untuk memantau perkembangan status gizi anak TK adalah KMS.

Kartu Menuju Sehat (KMS) TB/U merupakan alat yang spesifik dikembangkan untuk skrining untuk deteksi stunting anak usia 3-5 tahun. Alat ini sudah dilakukan uji sentitifitas dan spesifitas, dimana didapatkan nilai sensitifitas 91\%, dan spesifitas $92 \%$. Artinya alat ini sangat cocok untuk mendeteksi stunting (Sinaga, Alfridsyah, Sitanggang, \& Hadi, 2018)

\section{METODE PENELITIAN}

Jenis penelitian yang digunakan dalam penelitian ini adalah jenis penelitian deskriptif. Metode penelitian yang yang digunakan adalah survey dengan pendekatan cross sectional yaitu objek penelitian diukur atau dikumpulkan secara simultan (dalam waktu yang bersamaan). Penelitian ini dilakukan kepada 29 anak di Taman KanakKanak Azizah selama 10 (sepuluh) bulan (Januari- 
JKM (Jurnal Kebidanan Malahayati),Vol 7,No.2.April 2021,

ISSN (Print) 2476-8944 ISSN (Online) 2579-762X, Hal 310-318

Oktober 2020) di Kota Pangkalpinang Provinsi Bangka Belitung, Indonesia.

Data diperoleh melalui pengukuran dan penimbangan kepada anak-anak. Pengukuran yang dilakukan yaitu Tinggi badan dengan KMS yang ditempel di dinding, deteksi tumbuh kembang anak dengan KPSP serta penimbangan berat badan. Namun juga melakukan observasi pelaksanaan cuci tangan.

\section{HASIL DAN PEMBAHASAN}

Sekolah Taman Kanak-Kanak yang dijadikan sampel pada penelitian ini merupakan sekolah TK milik swasta atau yang dimiliki oleh perorangan atau kelompok orang yang menyatukan diri mendirikan dibawah Himpunan PAUD Indonesia (HIMPAUDI). TK Azizah memiliki ruangan Usaha Kesehatan Sekolah (UKS). Kegiatan UKS yang paling banyak dilakukan oleh sekolah dalam bentuk melakukan penyuluhan menyikat gigi dan Pemberian Makanan Tambahan (PMT) kepada murid TK. Rincian kegiatan UKS yang diselenggarakan oleh TK dapat dilihat pada tabel dibawah.

Hasil penelitian berdasarkan sampel yaitu anak TK sebanyak 29 anak berjenis kelamin laki- laki $(51,7 \%)$ dengan usianya adalah usia 2 - 4 tahun yaitu sebesar $62,1 \%$.

Tabel 1.

Kegiatan UKS di Taman Kanak-Kanak Azizah

\begin{tabular}{lcc}
\hline \multicolumn{1}{c}{ Kegiatan UKS } & Ada & Tidak Ada \\
\hline $\begin{array}{l}\text { Pemberian PMT } \\
\text { Praktik Cuci Tangan }\end{array}$ & $\checkmark$ & \\
$\begin{array}{l}\text { Praktik Sikat Gigi } \\
\begin{array}{l}\text { Penimbangan Berat } \\
\text { Badan }\end{array}\end{array}$ & $\checkmark$ & $\checkmark$ \\
$\begin{array}{l}\text { Pengukuran Tinggi } \\
\text { Badan }\end{array}$ & $\checkmark$ & \\
\hline
\end{tabular}

Tabel 2.

Karakteristik Anak Taman Kanak-Kanak Azizah

\begin{tabular}{lcc}
\hline \multicolumn{1}{c}{ Variabel } & Frekuensi & Presentase \\
\hline Jenis Kelamin & & \\
Perempuan & 14 & 48,3 \\
Laki - laki & 15 & 51,7 \\
Umur (bulan) & & \\
$0-24$ & 2 & 6,9 \\
$25-36$ & 9 & 31 \\
$37-48$ & 9 & 31 \\
$49-60$ & 6 & 20,7 \\
$61-72$ & 3 & 10,4 \\
\hline
\end{tabular}

Tabel 3.

Penilaian Status Gizi, Penyimpangan Perkembangan dan Perilaku Cuci Tangan

\begin{tabular}{lll}
\hline \multicolumn{1}{c}{ Variabel } & Frekuensi & Presentase \\
\hline Perilaku Cuci Tangan & & \\
Baik & 21 & 75 \\
Cukup & 5 & 17,9 \\
Kurang & 2 & 7,1 \\
Deteksi Dini Penyimpangan Perkembangan & & \\
Sesuai & 16 & 55,2 \\
Meragukan & 9 & 31 \\
Penyimpangan & 4 & 13,8 \\
Status Gizi & & \\
Pendek & 2 & 6,9 \\
Normal & 27 & 93,1 \\
\hline
\end{tabular}

\section{PEMBAHASAN}

Perilaku Cuci Tangan

Berdasarkan analisis data didapatkan hasil perilaku mencuci tangan anak dengan menggunakan pedoman cuci tangan dari WHO diperoleh data sebanyak 21 (75\%) telah dilaksanakan dengan baik (6 - 7 langkah) dan kurang baik sebesar $7,1 \%$.
Departemen Kesehatan RI (2007) menyatakan bahwa anak-anak usia dini baik pra sekolah (TK) maupu usia sekolah dasar (SD/MI) adalah sasaran utama dalam implementasi hidup sehat. Hal ini karena anak-anak seuisia ini masih sangat aktif dan berkumpul, bermain bersama teman-temannya, tak jarang anak-anak ini abai terhadap menjaga kebersihan badan utamanya mencuci tangan. Maka tak jarang mereka sangat 
rentan terhadap penyakit. Pembiasaan berpola hidup sehat harus terus digalakkan pada anak usia dini. Baik itu cuci tangan dengan sabun, memotong kuku atau menjaga lingkungan sekitar (Depkes, 2007)

Tangan adalah bagian tubuh kita yang paling banyak tercemar kotoran dan bibit penyakit. Ketika memegang sesuatu, dan berjabat tangan, tentu ada bibit penyakit yang melekat pada kulit tangan kita. Sehabis memegang pintu kamar kecil (sumber penyakit yang berasal dari tinja manusia), saat mengeringkan tangan dengan lap di dapur, memegang uang, lewat pegangan kursi kendaraan umum, gagang telepon umum, dan bagian-bagian di tempat umum, tangan hampir pasti tercemar bibit penyakit jenis apa saja. Kebiasaan mencuci tangan dengan sabun, adalah bagian dari perilaku hidup sehat. Cuci tangan dengan betul tidak hanya dipengaruhi oleh cara mencucinya, tetapi juga oleh air yang digunakan dan lap tangan yang digunakan. Berdasarkan studi Basic Human Services (BHS) di Indonesia tahun 2006, perilaku masyarakat dalam mencuci tangan adalah: setelah buang air besar $12 \%$, setelah membersihkan tinja bayi dan balita $9 \%$, sebelum makan $14 \%$, sebelum memberi makan bayi $7 \%$, dan sebelum menyiapkan makanan $6 \%$ (Departemen Kesehatan RI, 2008). Cuci tangan pakai sabun (CTPS) merupakan tindakan pencegahan terhadap penyakit yang ditularkan melalui tangan, misalnya diare dan infeksi saluran nafas atas. Hasil penelitian menunjukkan bahwa perilaku cuci tangan pada anak SD Di Kabupaten Malang dalam kategori baik sebesar $53,7 \%$, sedangkan diare dalam kriteria rendah sebesar 59,3\%. Kondisi ini didukung oleh penelitian (Burton et al., 2011 dan Pickering, Boehm, Mwanjali, \& Davis, 2010) menunjukkan bahwa cuci tangan dengan menggunakan sabun lebih efektif dalam memindahkan kuman dibandingkan dengan cuci tangan hanya dengan mengggunakan air. Beberapa hasil riset menunjukkan bahwa promosi perilaku cuci tangan, peningkatan kualitas air bersih dan sanitasi lingkungan telah terbukti mengurangi kejadian penyakit gastrointestinal, penyakit pernafasan dan menurunkan absensi murid pada negara berkembang (Chittleborough, C.R Nicholson, Young, Bell, \& Campbell, 2013).

Tindakan pemeliharaan kebiasaan cuci tangan perlu dipertahankan dengan dilakukan evaluasi apakah cuci tangan masih dilakukan. Schmidt, W-P (2009) mengatakan bahwa kendala struktural (penyediaan sarana air bersih) dapat mempengaruhi perilaku cuci tangan. Media masa mempunyai peran yang penting dalam promosi kebersihan diri termasuk cuci tangan, sehingga perlu dimanfaatkan dengan baik di era teknologi yang serba canggih ini.

Cuci tangan dengan betul tidak hanya dipengaruhi oleh cara mencucinya, tetapi juga oleh air yang digunakan dan lap tangan yang digunakan. Cuci tangan memakai sabun mutlak perlu, dan menggunakan sabun bukan sekedar lewat saja. Cuci tangan yang benar perlu teliti sampai ke bagian-bagian sela jari dan sela kuku. Semua bagian tangan jangan ada yang lupa untuk disabun, kalau perlu diulang berkali-kali, apalagi kalau niatnya untuk makan menggunakan tangan (tanpa sendok). Terkadang kita sudah benar cara mencuci tangan, tapi karena lap yang kita pakai kotor, maka sama saja cuci tangan kita tidak berguna, karena kita bisa terkena bibit penyakit yang berasal dari lap yang kotor. Perilaku cuci tangan akan berhasil ketika sudah tertanam kebiasaan dan juga tersedia sarana dan prasarana untuk cuci tangan. Penyediaan air bersih dan juga sabun untuk cuci tangan sangat diperlukan.

Berdasarkan hasil riset sekolah belum semua menyediakan fasilitas air mengalir untuk cuci tangan, sekolah yang sudah menggunakan kran sebesar $33 \%$, sedangkan $54 \%$ masih menggunakan kamar mandi. Kondisi ini menggambarkan bahwa sekolah sudah mulai menyadari pentingnya penyediaan sarana cuci tangan bagi siswanya. Berdasarkan observasi peneliti, sekolah yang letaknya di pinggiran (jauh dari kota) sarana untuk cuci tangan masih belum memadai, banyak yang tidak menyediakan. (Departemen Kesehatan RI, 2008) mengungkapkan bahwa cara CTPS yang benar adalah memerlukan sabun dan sedikit air mengalir. Air mengalir dari kran bukan keharusan, yang penting air mengalir dari sebuah wadah bisa berupa botol, kaleng, ember tinggi, gentong, jerigen, atau gayung. Tangan yang basah disabuni, digosok-gosok bagian telapak maupun punggungnya, terutama di bawah kuku minimal 20 detik. Bilas dengan air mengalir dan keringkan dengan kain bersih atau kibas-kibaskan di udara. Pemerintah masih perlu memberi perhatian terkait dengan penyediaan sarana cuci tangan di tempat umum termasuk sekolah, kalau dimungkinkan pemerintah membuat peraturan yang mewajibkan adanya sarana cuci tangan untuk tempat-tempat umum.

Upaya promotif dan preventif dalam rangka meningkatkan derajat kesehatan bangsa dan masyarakat dapat dilakukan dengan penerapan perilaku hidup bersih dan sehat. Kebiasaan mencuci tangan dengan sabun, adalah bagian dari perilaku hidup sehat yang merupakan salah satu 


\section{JKM (Jurnal Kebidanan Malahayati),Vol 7,No.2.April 2021, \\ ISSN (Print) 2476-8944 ISSN (Online) 2579-762X, Hal 310-318}

dari tiga pilar pembangunan bidang kesehatan yakni perilaku hidup sehat,(Purwandari,2015) penciptaan lingkungan yang sehat serta penyediaan layanan kesehatan yang bermutu dan terjangkau oleh semua lapisan masyarakat. Perilaku hidup sehat yang sederhana seperti mencuci tangan dengan sabun merupakan salah satu cara untuk meningkatkan kesadaran masyarakat tentang pemeliharaan kesehatan pribadi dan pentingnya berperilaku hidup bersih dan sehat. Harapannya dengan cuci tangan yang merupakan kegiatan sepele dan bernilai murah ini apabila dikerjakan secara rutin oleh seluruh masyarakat akan menurunkan berbagai penyakit menular dan meningkatkan status kesehatan masyarakat.

Pembiasaan cuci tangan sesuai standar kesehatan sesungguhnya dapat dilakukan dengan berbagai langkah. Selain melalui pembelajaran di sekolah oleh guru, juga dapat dilakukan oleh orang tua saat anak-anak sudah di rumah. Peran orang tua sangatlah penting, karena menurut Syantut (2018) orang tua adalah madrasah atau sekolah juga bagi anak-anak jika mereka sudah sampai di rumah. Karena orang tua adalah laksanaka sekolah, maka orang tua dapat juga melaksanakan transfer of knowledge (menyampaikan pengetahuan) selain tentu saja transfer of value (suri tauladan yang baik). Dari konsep ini orang tua amatlah memiliki peran yang sangat penting juga dalam memberikan pembelajaran sekaligus praktik menjaga kebersihan tangan sesuai langkahlangkah kesehatan. Selain itu, mereka juga memili peran penting dalam mensuasanakan kehidupan kesehatan berupa bersih tangan dari bibit penyakit yang sehat dan benar di keluarga sejak dini.

\section{Deteksi Tumbuh Kembang dengan Form KPSP}

Berdasarkan analisis data didapatkan hasil deteksi dini penyimpangan anak dengan menggunakan Kuesioner Pra Skrining Perkembangan (KPSP) sebanyak $16 \quad(55,2 \%)$ sesuai dengan perkembangan, namun terdapat 9 $(31 \%)$ anak meragukan dan $4 \quad(13,8 \%)$ kemungkinan mengalami penyimpangan. Faktor penentu kualitas tumbuh kembang anak adalah potensi genetik-heredo konstituinal (intrinsik) dan peran lingkungan (ekstrinsik). Gangguan tumbuh kembang terjadi bila ada faktor genetik dan atau karena faktor lingkungan yang tidak mampu mencukupi kebutuhan dasar tumbuh kembang anak. Peran lingkungan sangat penting untuk mencukupi kebutuhan dasar tumbuh kembang anak yaitu kebutuhan bio-psikosial terdiri dari kebutuhan biomedis/'asuh' (nutrisi, imunisasi, higiene, pengobatan, pakaian, tempat tinggal, sanitasi lingkungan dan lain-lain) dan kebutuhan psikososial/asih dan asah (kasih sayang, penghargaan, komunikasi, stimulasi bicara, gerak, sosial, moral, intelegensi dan lain-lain) sejak masa konsepsi sampai akhir remaja (Kementrian Kesehatan RI, 2016).

Kualitas masa depan anak sangat ditentukan pada periode umur anak bawah lima tahun (balita). Proses tumbuh kembang berjalan dengan cepat, baik fisik, kognitif, keterampilan, sosial, emosi, termasuk perkembangan kepribadiannya. Pada periode ini perkembangan kemampuan berbahasa, berkreativitas, kesadaran social, emosional dan intelegensia berjalan sangat cepat dan merupakan landasan perkembangan berikutnya. Perkembangan setiap anak memiliki keunikan tersendiri dan kecepatan pencapaian perkembangan tiap anak berbeda. Seorang anak dapat mengalami keterlambatan perkembangan di hanya satu ranah perkembangan saja, atau dapat pula di lebih dari satu ranah perkembangan. Keterlambatan perkembangan umum merupakan keadaan keterlambatan perkembangan yang bermakna pada dua atau lebih ranah perkembangan. Melakukan skrining atau mendeteksi secara dini adanya penyimpangan tumbuh kembang balita berarti melakukan deteksi dini penyimpangan tumbuh kembang termasuk menindaklanjuti setiap keluhan orang tua terhadap masalah tumbuh kembang anaknya.

Masa balita merupakan periode penting dalam tumbuh kembang anak, karena pada masa ini perkembangan kemampuan berbahasa, berkreativitas, kesadaran sosial,emosional, dan intelegensi berjalan sangat cepat dan merupakan landasan perkembangan selanjutnya. Perkembangan anak sangat dipengaruhi oleh banyak faktor. Menurut Sulistyawati (2014) menyatakan faktor-faktor yang mempengaruhi perkembangan anak meliputi faktor genetik dan faktor lingkungan. Salah satu faktor lingkungan yang berpengaruh terhadap perkembangan adalah faktor postnatal yang meliputi jenis kelamin, umur, dan lain-lain.

Berdasarkan tabel 2 menunjukkan bahwa jumlah antara responden laki-laki dan perempuan adalah hampir sama yaitu sebanyak 15 dan 14 responden ( $\pm 50 \%$ ). Menurut Hurlock (1978) dalam Ariyanti, (2010) menyatakan bahwa dibandingkan dengan anak perempuan, anak laki-laki tertinggal dalam belajar berbicara. Pada setiap jenjang umur, kalimat anak laki-laki lebih pendek dan kurang betul tata bahasanya, kosa kata yang diucapkan lebih sedikit dan pengucapannya kurang tepat daripada 
anak perempuan. Hal ini sesuai dengan hasil pemeriksaan perkembangan balita yang dilakukan peneliti dengan menggunakan KPSP yaitu dari 29 balita dengan perkembangan meragukan dan menyimpang ditemukan 12 balita $(41,3 \%)$ mengalami keterlambatan dalam bicara dan bahasa, dan 7 balita (24\%) diantaranya adalah jenis kelamin laki-laki.

Menurut Solihin, Malateki, Anwar, \& Sukandar (2013), faktor-faktor yang berhubungan signifikan dengan tingkat perkembangan kognitif balita adalah status gizi balita, usia balita, lama mengikuti PAUD, dan praktik pengasuhan balita oleh ibu. Semakin meningkat usia balita maka semakin meningkat pula tingkat perkembangan motorik halus, tingkat perkembangan motorik kasar, dan tingkat perkembangan kognitif. Setiap penambahan satu bulan usia balita, akan menambah tingkat perkembangan motorik kasar balita sebesar 0,46 persen.

Penelitian Fadlyana et al (2003) menunjukkan bahwa keterlambatan perkembangan balita merupakan masalah kesehatan, dengan angka kejadian $29,3 \%$ di pedesaan dan $18,7 \%$ di perkotaan. Tingginya angka keterlambatan yang ditemukan merupakan potensi untuk menurunkan kualitas hidup di kemudian hari sehingga perlu diupayakan bagaimana cara mengatasinya. Anak yang mengalami penyimpangan perkembangan bila dibiarkan saja, maka sebagian besar (89\%) akan mengalami kegagalan di sekolahnya. Faktor lingkungan yang dapat menyebabkan penyimpangan tumbuh kembang anak di Negaranegara yang sedang berkembang termasuk Indonesia umumnya dilatarbelakangi oleh kemiskinan dan ketidaktahuan masyarakat tentang proses tumbuh kembang (Fadlyana et al., 2003)

\section{Pengukuran Tinggi Badan dengan KMS Dinding}

Grafik KMS Dinding dipenuhi dengan warna merah, kuning, hijau muda dan hijau tua. Merah berarti sangat pendek, kuning berarti pendek, hijau muda berarti normal dan hijau tua berarti tinggi.

Berdasarkan tabel 3, hasil pengukuran menggunakan KMS dinding pada sekolah TK menunjukkan bahwa terdapat sebesar $6,9 \%$ anakanak yang dengan hasil ukur menggunakan KMS dinding berada pada warna kuning, sedangkan yang berada pada hijau muda lebih besar yaitu $86,2 \%$ dan warna hijau tua sebesar $6,9 \%$. Hasil tersebut menyimpulkan bahwa berdasarkan penggunaan KMS dinding, terdeteksi anak TK yang mengalami stunting sebesar $6,9 \%$ dan anak yang normal sebesar 93,1\% di TK Azizah. Kondisi stunting ini lebih rendah dibandingkan dengan kondisi stunting nasional sebesar 30,8\%.3 Anak yang mengalami stunting akan mengalami penurunan sistem imunitas dan meningkatkan resiko terkena penyakit infeksi serta kecenderungan untuk menderita penyakit darah tinggi, diabetes melitus, jantung, dan obesitas akan lebih tinggi ketika anak stunting sudah dewasa (Bryce, D, I, D, \& P, 2008 dan AL-Rahmad, Miko, \& Hadi, 2013). Hasil penelitian ini sejalan dengan penelitian yang pernah dilakukan (Sinaga et al., 2018) pada 180 anak PAUD yang tersebar 8 sekolah PAUD di Deli Serdang, Sumatera Utara. Dimana didapatkan $39(21,7 \%)$ anak PAUD mengalami stunting dan $142 \quad(78,3 \%)$ normal pertumbuhannya. Selanjutnya, untuk mengukur stunting diperlukan alat serta metoda yang mudah dipahami oleh guru PAUD. Pengembangan alat pengukuran tinggi badan (KMS dinding) dapat dijadikan alat yang baku pada pengukuran tinggi badan di PAUD.

Penelitian Sinaga, Alfridsyah, Sitanggang, \& Hadi (2018) menyatakan bahwa penggunaan KMS sangatlah mudah untuk digunakan sebagai alat pengukuran tinggi badan pada anak PAUD. Namun ada beberapa penilaian guru baru yang dirasakan sulit seperti membaca kurva pertumbuhan sesuai jenis kelamin, penentuan bulan serta membaca tinggi badan anak. KMS dinding diharapkan mampu memberikan kontribusi kepada guru PAUD dalam memantau pertumbuhan tinggi badan anak PAUD.

Walaupun ada berbagai alat skrining kesehatan yang dikembangkan, terutama untuk meningkatkan keakuratan alat, adapun pengembangan alat tersebut kebanyakan hanya terbatas pada pasien usia lanjut usia dan orang dewasa di rumah sakit (Spagnuolo, Liguoro, Chiatto, Mambretti, \& Guarino, 2013). Alat tinggi badan merupakan salah satu alat ukur yang digunakan oleh PAUD sebagai media pengukur tinggi badan namun untuk mengefesiensi pekerjaan guru PAUD, maka diperlukan sebuah alat ukur sederhana, murah, akurat serta mudah dalam penggunaannya sehingga bisa mengukur tinggi badan dengan baik (Hadi, Affan, Alfridsyah, \& Rahmad, 2019).

Mendeteksi pertumbuhan bayi ataupun balita secara cermat dapat menggunakan Kartu Menuju Sehat (KMS). Kartu Menuju Sehat berfungsi sebagai alat bantu pemantauan gerak pertumbuhan dan perkembangan, karena isi KMS selain grafik untuk pemantauan pertumbuhan juga di dalamnya terdapat tahap - tahap perkembangan anak dari lahir sampai umur 72 bulan (Palasari, 2012) 


\section{JKM (Jurnal Kebidanan Malahayati),Vol 7,No.2.April 2021, ISSN (Print) 2476-8944 ISSN (Online) 2579-762X, Hal 310-318}

Untuk pendidikan di Indonesia, penggunaan bagan pertumbuhan sederhana di sekolah ini sangat diharapkan karena pada tahun 2014, jumlah sekolah TK mencapai 75.000 , ada 5 juta siswa, di antaranya $80 \%$ (3,5 juta) berusia 4-5 tahun, yang menjadikan pemantauan pertumbuhan anak sebagai program wajib (Solihin, Malateki, Anwar, \& Sukandar, 2013).

\section{SIMPULAN}

KMS Dinding dapat mendeteksi terjadinya stunting pada anak TK, terdapat anak yang kemungkinan mengalami penyimpangan dan sebagian besar anak telah mencuci tangan dengan baik sesuai dengan pedoman $\mathrm{WHO}$

\section{SARAN}

Diharapkan kepada pengelola sekolah TK untuk melakukan deteksi stunting dengan KMS dinding ini karena alat ini sangat berguna dalam pemantauan pertumbuhan anak didik TK. Selanjutnya diperlukan promosi dan sosialisasi di tingkat Dinas kesehatan untuk pengenalan alat deteksi stunting ini. Saran juga disampaikan kepada pihak sekolah agar terus memberikan motivasi pada siswa untuk membiasakan diri cuci tangan menggunakan sabun di lingkungan sekolah dan rumah, guna mencegah timbulnya penyakit yang disebabkan oleh tangan yang kotor. Pihak sekolah diharapkan terus dapat melakukan deteksi dini tumbuh kembang anak agar dapat segera dilakukan upaya perbaikan jika ditemukan kondisi penyimpangan pada tumbuh kembang anak

\section{DAFTAR PUSTAKA}

Allender, J. A., Rector, C., \& Warner, K. (2010). Community and Public Health Nursing: Promoting the Public's Health. China: Lippincott Williams \& Wilkins.

AL-Rahmad, A., Miko, A., \& Hadi, A. (2013). Kajian stunting pada anak balita ditinjau dari pemberian ASI eksklusif, MP-ASI, status imunisasi dan karakteristik keluarga di Kota Banda Aceh. Jurnal Kesehatan IImiah Nasuwakes, 6(2), 169-184.

Ardhiyarini. (2008). Faktor-Faktor yang mempengaruhi personal hygiene anak usia sekolah di SD Negeri Pleret Kecamatan Panjatan Kabupaten Kulon Progo. Yogyakarta: Universitas Muhammadiyah Yogyakarta. Retrieved Januari 2020

Ariyanti, A. (2010). Perbedaan Perkembangan Anak Balita pada Ibu Bekerja dan Ibu Tidak Bekerja Penilaian Menggunakan Metode
Denver II. Surakarta: Universitas Sebelas Maret.

Burton, M., Cobb, E., Donachie, P., Judah, G., Curtis, V., \& Schmidit, W. (2011). The effect of hand washing with water or soap on bacterial contamination of hands. Int. J. Environ. Res. Public Health, 8, 97-104.

Chittleborough, C.R Nicholson, A. ., Young, E., Bell, S., \& Campbell, R. (2013). Implementation of an educational intervention improve hand washing in primary schools: process evaluation within a randomized controlled trial. BMC Public Health, 13(757), 2-11.

Departemen Kesehatan RI. (2007). Panduan Promosi Kesehatan di Sekolah. Jakarta: Depkes Rl.

Edelman, C., \& Mandle, C. (2010). Health Promotion Throughtout The Life Span. St.Louis, Missouri: Mosby Inc.

Fadlyana, E., Alisjahbana, A., Nelwan, I., Noor, M., Selly, \& Sofiatin, Y. (2003). Pola Keterlambatan Perkembangan Balita di Daerah Pedesaan dan Perkotaan Bandung, serta Faktor-faktor yang Mempengaruhinya. Sari Pediatri, 4(4), 168-175.

Grodner, M. L., \& Walkingshaw, B. (2007). Foundations and clinical applications of nutrition : a Nurdin approach. Fourth edition. St. Louis Missouri: Mosby Inc.

Hadi, A., Affan, I., Alfridsyah, A., \& Rahmad, A. A. (2019). Efektifitas pendidikan gizi mengunakan KMS dinding indeks TB/U terhadap tindakan guru PAUD dalam pemantauan pertumbuhan anak usia 4-5 tahun pada anak sekolah PAUD. Aceh Nutrition Journal, 4(1), 65-73.

Harjatmo, T. P., Par'i, H. M., \& Wiyono, S. (2017). Penilaian Status Gizi. Jakarta: Kementerian Kesehatan RI.

Kementrian Kesehatan RI. (2016). Pedoman Pelaksanaan Stimulasi, Deteksi dan Intervensi Dini Tumbuh Kembang Anak Ditingkat Pelayanan Kesehatan Dasar. Jakarta: Kementrian Kesehatan RI.

Maurer, F. A., \& Smith, C. M. (2013). Community/ Public Health Nursing Practice: Health for Families and Populations. Canada: Elsevier HEalth Sciences.

Notoatmodjo, S. (2010). Promosi Kesehatan; Teori dan Aplikasi. Jakarta: Rineka Cipta.

Novieastari, E., Ibrahim, K., Deswani, \& Ramdaniati, S. (2020). Dasar-Dasar Keperawatan Volume 1, 9th Indonesia Edition. Singapore: Elsevier. 


\section{Antarini, Eka Safitri Yanti}

Palasari, W. (2012). Skills On The Detection Of Early Mother Flower Grow With Baby. Jurnal STIKES, 11-20.

Pender, N. J., Murdaugh, C. L., \& Parsons, M. A. (2011). Health Promotion in Nursing Practice, 6th Edition. South Carolina: Pearson.

Pickering, A. ., Boehm, A. ., Mwanjali, M., \& Davis, J. (2010). Efficacy of waterless hand hygiene compared with hand washing with soap: a field study in Dar es Salaam, Tanzania Am. J. Trop. Med. Hyg., 82(2), 270-278. doi:10.4269/aitmh.2010.09-0220. Journal Tropical Medicine Hygene, 82(2), 270-278.

Purwandari, R., \& Ardiana, A. (2015). Hubungan antara perilaku mencuci tangan dengan insiden diare pada anak usia sekolah di Kabupaten Jember. Jurnal Keperawatan, 4(2).

Satria, H. (2017). PENGARUH PENDIDIKAN KESEHATAN TERHADAP PERSONAL HYGIENE SISWA KELAS III SD LANGKAI 1 PALANGKA RAYA (Doctoral dissertation, Faculty of Agriculture Merdeka University Surabaya).

Schmidt, W-P., et al. (2009). Determinants of hand washing practices in Kenya: the role of media exposure, poverty and infrastructure. Tropical Medicine and International Health. Tropical Medicine and International Health, 14(12), 1534-1541. https://doi.org/10.1111/j.1365- 3156.2009.02404.x

Sinaga, H. T., Alfridsyah, Sitanggang, B., \& Hadi, A. (2018). A Simple Nutrition Screening Tool for Detecting Stunting of Pre-Schoolers: Development and Validity Assessment. Pakistan Journal of Nutrition, 236-241.

Solihin, Malateki, Anwar, \& Sukandar. (2013). Kaitan antara Status Gizi, Perkembangan Kognitif, dan Perkembangan Motorik pada Anak Usia Prasekolah. Jurnal Gizi Dan Makanan, 62-72.

Spagnuolo, M., Liguoro, I., Chiatto, F., Mambretti, D., \& Guarino, A. (2013). Application of a score system to evaluate the risk of malnutrition in a multiple hospital setting. Italian Journal of Pediatrics, 39(1).

Sulistyawati, A. (2014). Deteksi Tumbuh Kembang Anak. Jakarta: Salemba Medika.

Supariasa, I. D., Bakri, B., \& Fajar, I. (2010). Penilaian Status Gizi. Jakarta: EGC.

Syantut, K. A. (2018). Mendidik Buah Hati di Rumah dalam Rumahku Madrasah Pertamaku. Jakarta: Maskana Media.

Ulfa, M. (2018). Analisa Deteksi Dini dan Stimulasi Peerkembangan Anak Usia Prasekolah. Jurnal IImiah IImu Kesehatan, 6(3), 200-209.

Wright, Shogbamimu, Akinbami, Adebisi, Senbanjo, \& Iolade. (2018). Nutritional status of children in a well-child clinic in Lagos, Nigeria. African J Food, Agric Nutr Dev, 13602-16. 